\title{
ANL/TD/CP-98295
}

\section{STRUCTURAL DESIGN CRITERIA FOR HIGH HEAT FLUX COMPONENTS*}

by

Saurin Majumdar

Fusion Power Program

Argonne National Laboratory

Argonne, IL 60439 USA

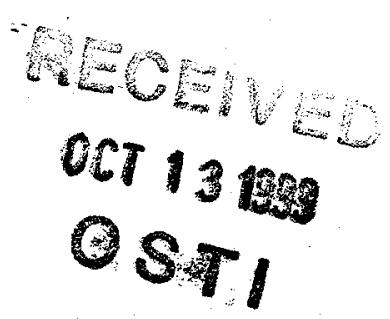

June, 1999

To be presented at the 5th International Symposium on Fusion Nuclear technology, September 19-24, 1999, Rome.

* Work supported by Office of Fusion Energy, U.S. Department of Energy, under Contract No W-31-109-Eng-38. 


\section{DISCLAIMER}

This report was prepared as an account of work sponsored by an agency of the United States Government. Neither the United States Government nor any agency thereof, nor any of their employees, make any warranty, express or implied, or assumes any legal liability or responsibility for the accuracy, completeness, or usefulness of any information, apparatus, product, or process disclosed, or represents that its use would not infringe privately owned rights. Reference herein to any specific commercial product, process, or service by trade name, trademark, manufacturer, or otherwise does not necessarily constitute or imply its endorsement, recommendation, or favoring by the United States Government or any agency thereof. The views and opinions of authors expressed herein do not necessarily state or reflect those of the United States Government or any agency thereof. 


\section{DISCLAIMER}

Portions of this document may be illegible in electronic image products. Images are produced from the best available original document. 


\title{
STRUCTURAL DESIGN CRITERIA FOR HIGH HEAT FLUX COMPONENTS*
}

\author{
Saurin Majumdar \\ Fusion Power Program, Argonne National Laboratory, Argonne, IL 60439
}

\begin{abstract}
The high temperature design rules of the ITER Structural Design Criteria (ISDC), are applied to first wall designs with high heat flux. The maximum coolant pressure and surface heat flux capabilities are shown to be determined not only by the mechanical properties of the first wall material but also by the details of the blanket design. In a high power density self-cooled lithium blanket, the maximum primary stress in the first wall is controlled by many of the geometrical parameters of the blanket, such as, first wall span, first wall curvature, first wall thickness, side wall thickness, and second wall thickness. The creep ratcheting lifetime of the first wall is also shown to be controlled by many of the same geometrical parameters as well as the coolant temperature.
\end{abstract}

According to most high temperature design codes, the time-dependent primary membrane stress allowables are based on the average temperature (ignoring thermal stress). Such a procedure may sometimes be unconservative, particularly for embrittled first walls with large temperature gradients. The effect of secondary (thermal) stresses on the accumulation of creep deformation is illustrated with a vanadium alloy flat plate first wall design.

\section{Introduction}

It has been customary in past design studies [1-2] to set limits to the maximum surface heat flux capability of a design on the basis of explicit or implicit peak temperature limits for the structural alloys used in plasma facing components, without any detailed consideration or analysis of damages due to creep, neutron or helium-induced embrittlement. A purpose of this paper is to show that such limits can be exceeded if detailed deformation or damage analyses together with material properties data show that the maximum stresses and strains due to the expected loadings can meet the lifetime requirements for the design. A lithium-cooled vanadium blanket with curved first wall is considered as an example [3]. It is shown that the maximum surface heat flux capability of the first wall depends not only on the properties of the first wall material but also on the details of the design and the structural design criteria used to set limits on stresses and strains. For the purposes of this paper, the ITER Structural Design Criteria

\footnotetext{
* Work supported by Office of Fusion Energy, U.S. Department of Energy, under Contract No W-31-109-Eng-38.
} 
(ISDC) [4-5] is used as the structural design criteria and a vanadium alloy is assumed to be the structural alloy.

A second purpose is to examine the conservativeness, or a lack thereof, of the usual practice in high temperature design codes, such as the ISDC and the ASME Code in which the primary stress allowables are based on the average wall temperature, and thermal stresses are ignored. Although such a procedure is justified for unirradiated materials and for cases where the temperature gradients are small, it has not been established that the same is true for the design of high-heat-flux first walls (high neutron wall loading) whose tensile and creep ductility may be severely reduced by neutron and He-induced embrittlement. In such cases, the temperature of the plasma facing side of the first wall can be well into a temperature regime where thermal creep and He-embrittlement are important, but a significant fraction of the wall may still be at temperatures where thermal creep and He-embrittlement are negligible. A flat plate that is cooled on one side and subjected to a surface heat flux on the other is analyzed to illustrate the problems.

\section{High Temperature Design Rules}

Since the high temperature section of ISDC has not been widely used by the fusion design community in the past, its main rules are reviewed briefly. However, fatigue, creep-fatigue, and unstable brittle fracture from pre-existing flaws will not be considered here. It should be remembered that the low temperature design rules are also applicable at high temperature. It will be assumed that the minimum operating temperature of the first wall will be sufficiently high ( $400^{\circ} \mathrm{C}$ for vanadium alloys) so that the rules of ISDC that address irradiation-induced losses of uniform elongation and ductility do not limit the surface heat flux capability. Note that satisfaction of the well known $3 \mathrm{~S}_{\mathrm{m}}$ rule for low temperature ratcheting is not sufficient to prevent ratcheting at high temperatures.

\subsection{Time-dependent allowable primary stress intensity $\left(S_{t}\right)$}

$\mathrm{S}_{\mathrm{t}}$ is a time and temperature-dependent allowable primary stress intensity defined as the least of the following:

(1) two thirds of the minimum stress corresponding to average creep rupture time $t$ at temperature $\mathrm{T}$,

(2) $80 \%$ of the minimum stress corresponding to time $t$ and temperature $T$ for onset of tertiary creep, and

(3) minimum stress to cause a creep strain of $\min \left[1 \%, \varepsilon_{C} / 5\right]$ in time $t$ and temperature $T$, where $\varepsilon_{C}$ is the minimum creep ductility. 
Available data $[6,7]$ for creep rupture time and time to $1 \%$ creep strain of two vanadium alloys are plotted in Figs. 1a and $1 \mathrm{~b}$, respectively, using a Larson-Miller parameter. In the absence of data on tertiary creep, the variation of $S_{t}$ (ignoring the tertiary creep limitation) for vanadium alloys with time and temperature are shown in Fig. 2. Note that if the creep ductility of the alloy is reduced to $1 \%$, e.g., due to He-embrittlement, the value of $S_{t}$ might be reduced from those shown in Fig. 2. Fig. 2 also includes the variation of the time-independent primary stress allowable $S_{m}$ with temperature.

\subsection{Creep damage limits}

To guard against creep damage, the following limits must be satisfied:

$$
\begin{aligned}
& P_{m} \leq S_{t}\left(T_{m}, t\right) \\
& P_{L}+P_{b} / K_{t} \leq S_{t}\left(T_{m}, t\right)
\end{aligned}
$$

where $t$ is the design lifetime, $T_{m}$ is the section averaged temperature, $P_{m}, P_{L}$ and $P_{b}$ are general primary membrane, local primary membrane and primary bending stress intensities, respectively, and $\mathrm{K}_{\mathrm{t}}=(\mathrm{K}+1) / 2$ where $\mathrm{K}$ is the bending shape factor. If the lifetime involves variable stress and temperature history, Eqs. $1 \mathrm{a}-\mathrm{b}$ are replaced by limits on usage fraction sums.

\subsection{Creep-ratcheting limit}

The ISDC provides several alternative rules of varying degree of conservatism to guard against ratcheting at high temperatures. The rule that is the least conservative has been used in this paper and is described here. According to this rule, the following low-temperature ratcheting limit based on Bree diagram has to be satisfied first:

$$
Y \leq \begin{cases}\frac{1}{X} & \text { for } 0 \leq X \leq 0.5 \\ 4(1-X) & \text { for } 0.5<X \leq 1\end{cases}
$$

where

$$
X=\frac{P_{m}}{S_{y}} \text { or } X=\frac{P_{L}+\frac{P_{b}}{K}}{S_{y}} \text { and } Y=\frac{\Delta[P+Q]}{S_{y}} \text {, }
$$

$\Delta P$ and $\Delta Q$ are the primary and secondary stress intensity ranges and the yield stress $S_{y}$ is evaluated at the average of the thickness-averaged temperatures at the "cold" and "hot" ends of the cycle. 
Next, the high temperature ratcheting limit should be satisfied by first calculating an effective core stress $\sigma_{\mathrm{c}}$ for creep calculations as follows:

$$
\sigma_{\mathrm{c}}=\mathrm{ZS}_{\mathrm{yL}}
$$

where $S_{y L}$ is the $S_{y}$ value at the "low" temperature extreme of the cycle and $Z$ is a creep stress parameter defined in terms of $\mathrm{X}$ and $\mathrm{Y}$,

$$
\begin{aligned}
& Z=X \text { for } X+Y 1 \\
& Z=Y+1-2 \sqrt{(1-X) Y} \text { for } 1-X \quad Y<1 /(1-X) \\
& Z=X Y \text { for } Y>1 /(1-X)
\end{aligned}
$$

The total creep strain accumulated during the lifetime due to a stress $1.25 \sigma_{\mathrm{c}}$ should be less than $\min \left[1 \%, \varepsilon_{\mathrm{c}} / 5\right]$ where $\varepsilon_{\mathrm{c}}$ is the minimum creep ductility during the cycle. If the lifetime involves more than one types of cycles of stress and temperature, the criterion is satisfied by the use of usage fraction sums.

The variations of maximum allowable cyclic secondary (thermal) stress intensity range with steady primary stress intensity for $\mathrm{V}-4 \mathrm{Cr}-4 \mathrm{Ti}$ at various peak temperatures and for design lifetimes of $25,000 \mathrm{~h}$ and $80,000 \mathrm{~h}$ are shown in Figs. $3 \mathrm{a}$ and $3 \mathrm{~b}$, respectively. The plots assume a coolant (lithium) inlet temperature of $500^{\circ} \mathrm{C}$ and a film temperature drop of $50^{\circ} \mathrm{C}$ at the coolant-first wall interface (corresponds to a heat transfer coefficient of $40,000 \mathrm{~W} / \mathrm{m}^{2} /{ }^{\circ} \mathrm{C}$ at a surface heat flux of $2 \mathrm{MW} / \mathrm{m}^{2}$ ).

\section{High power density self-cooled lithium blanket}

The cross-section of a design configuration that is currently under consideration [3] is shown in Fig. 4. The first wall is curved in order to maximize its toroidal span by increasing its capability to resist the coolant pressure. For the purpose of analysis, a unit poloidal thickness (generalized plane strain) of the blanket with a coolant pressure of $0.5 \mathrm{MPa}$ is considered. The pressure exerted by the beryllium $(\mathrm{Be})$ and titanium carbide (TiC) layers on the surrounding blanket structures is assumed to be $0.1 \mathrm{MPa}$. Detailed finite element analyses have shown that the maximum primary stress in the first wall is a strong function of the thickness, height $h$ and toroidal span of the first wall, and the thicknesses of the side wall and the second wall. In order to keep the thermal stresses within acceptable limits, the first wall thickness is kept constant at $4 \mathrm{~mm}$. This still leaves a number of geometrical parameters which, if necessary, can be chosen to optimize the surface heat flux capability of the design while at the same time satisfy the various design rules. After a number of trial analyses, the following parameters were chosen as the reference geometry for the blanket, ensuring that the low temperature and high temperature primary stress limits are satisfied: 
First wall toroidal span $=0.4 \mathrm{~m}$, first wall height $\mathrm{h}=10 \mathrm{~cm}$, first wall thickness $=4 \mathrm{~mm}$, side wall thickness $=10 \mathrm{~mm}$, and second wall thickness $=8 \mathrm{~mm}$.

For the purpose of this paper, the surface heat flux on the first wall is treated as a variable while the temperature distribution in the rest of the blanket is held constant at a level given in ref. 3 .

\subsection{Surface heat-flux induced stresses}

The thermal stress in the first wall due to the surface heat flux is controlled by the generalized plane strain assumption of the model and is, therefore, relatively insensitive to all the blanket geometrical parameters except the first wall thickness (which is assumed to be fixed at 4 $\mathrm{mm}$ ). However, because of the interplay between primary stress and secondary stress, the blanket geometry has a significant influence on the creep ratcheting lifetime of the first wall. The surface heat flux capability and the lifetime numbers quoted here should be treated as approximate because calculations with Larson-Miller parameter plots that are derived from limited data are usually subject to large uncertainty.

\subsubsection{Second wall thickness}

The second wall thickness has a significant influence on the lifetime requirement of the first wall. Fig. 5 shows the allowable creep rupture time due to primary stresses and the allowable lifetime for satisfying creep ratcheting rule as functions of the second wall thickness. Note that the creep ratcheting rule (steady primary plus cyclic secondary stresses) puts a more stringent requirement on the lifetime than the creep rupture rule (steady primary).

\subsubsection{Coolant temperature}

Because of the exponential dependence of creep rate on temperature, the coolant temperature has a significant influence on the first wall creep ratcheting lifetime. Fig. 6 shows that by decreasing the coolant temperature by $30^{\circ} \mathrm{C}$, the creep ratcheting lifetime at a surface heat flux of $2 \mathrm{MW} / \mathrm{m}^{2}$ can be increased by a factor of $>5$.

\section{Limits for high heat flux components}

In most high temperature structural design criteria, the primary stress limits (e.g., Eqs 1 ab) are based on the average section temperature and are satisfied without any consideration of the thermal stresses. These assumptions are justified if the through-thickness temperature gradients are small and the material has sufficient creep ductility to relax out the thermal stresses without incurring significant damage. However, these assumptions may not always be valid for high heat flux components of advanced fusion reactor blankets. The implications for high heat flux components are explored here with the example of a $6 \mathrm{~mm}$ thick flat plate under generalized plane strain deformation and subjected to a constant primary membrane stress of $50 \mathrm{MPa}$ and a surface heat flux on one face and a fixed coolant side metal temperature on the other. Since 
steady state creep data for $\mathrm{V}-4 \mathrm{Cr}-4 \mathrm{Ti}$ were not available, calculations were performed using data for V-5Ti-2Cr as reported in [7] and shown in Fig. 7. As before, the results, which are based on considerable extrapolation in the data using a Larson-Miller parameter, are uncertain and should be used for qualitative discussions only.

Fig. 8a shows the temperature distribution in a plate due to a surface heat flux of $2 \mathrm{MW} / \mathrm{m}^{2}$ with the cold side held at $400^{\circ} \mathrm{C}$. Fig. 8a also shows the initial stress distribution and the stress distribution after $1000 \mathrm{~h}$. Note that the peak compressive stresses in the hot zone $\left(>650^{\circ} \mathrm{C}\right)$ of the plate are relaxed significantly at the expense of a slight reduction of the tensile stresses in the rest of the plate that is cooler. Fig. $8 \mathrm{~b}$ shows similar quantities for a plate with the cold side held at $650^{\circ} \mathrm{C}$ and subjected to a surface heat flux of $1 \mathrm{MW} / \mathrm{m}^{2}$. Contrast the stress relaxation behaviors in the two cases. Significant relaxation of tensile stresses and little relaxation of compressive stresses occur in the latter case because of the difference in the magnitudes of the stresses in the two cases. Relaxation of the compressive stresses in the first case occurs vary rapidly - the peak compressive stress is halved in about $50 \mathrm{~h}$, as shown in Fig. 9a. Further, the relaxation occurs with an accumulated compressive membrane creep strain of $0.01 \%$ (i.e., no creep damage). With increasing time, this creep rate will ultimately be reduced to zero and finally become tensile because the net primary force on the plate is tensile. In contrast, relaxation of the compressive stresses in the second case (Fig. 9b) occurs much more gradually and the accumulated membrane creep strain is tensile and rising (i.e., potentially damaging) from the very beginning.

In the above examples, although the two plates have the same primary membrane stress, they may require significantly different times to accumulate a membrane creep strain of $1 \%$ (see Section 2.1). The difference will be magnified if the creep ductility of the material is reduced to $<1 \%$. In contrast, the ISDC or the ASME code implicitly assumes that secondary (thermal) stresses do not influence the time to accumulate $1 \%$ membrane creep strain because generally they average out to zero, which is a reasonable assumption provided thermal stresses are small and the material has sufficient creep ductility. Since creep rate varies nonlinearly with stress as well as temperature, a limit on average creep strain that is set using average temperature and average stress may give unconservative results for the case of high thermal stress with large temperature gradient, particularly if the material is embrittled. This is illustrated in Fig. 10 which shows plots of the allowable primary membrane stress required to accumulate $1 \%$ membrane creep strain in $1000 \mathrm{~h}$ at a given average temperature, including and excluding thermal stress. The solid lines in Fig. 10 represent the allowable stresses computed with the actual time-dependent stress (primary plus thermal) and temperature distribution in the plate, while the dashed lines denote the code primary membrane stress allowables calculated with average temperature and ignoring thermal stress. Note that if the coolant side temperature of the plate is low $\left(<500^{\circ} \mathrm{C}\right)$, the code procedure will yield unconservative values for the allowable stress. Qualitatively similar behavior should be expected from first wall designs that are more complicated than a simple plate. 


\section{Conclusions}

Rules of the high temperature section of the ISDC are reviewed to show that creep deformation and rupture time data will be needed to develop the design curves for a blanket/first wall operating in the creep regime. If embrittlement due to helium and/or irradiation adversely affects the creep and tensile properties of the blanket material, the damaging effects can be accounted for by the current design rules after suitably modifying the time-independent and timedependent stress allowables of the code. However, to achieve this, mechanical properties data that include such embrittlement effects will be needed.

The maximum primary stress in the first wall of the high power density self-cooled lithium blanket is controlled by many of the geometrical parameters of the blanket, such as, first wall span, first wall height, first wall thickness, side wall thickness, and second wall thickness. In contrast, the maximum thermal stress in the first wall due to surface heat flux is relatively insensitive to the same parameters. However, because of the combined effect of primary and secondary stresses on creep ratcheting, the blanket geometrical parameters have a significant influence on the creep ratcheting lifetime of the blanket. Thus, by suitably choosing the key blanket geometrical parameters and the coolant temperature, the surface heat flux capability of the blanket can be optimized with a reasonably long creep ratcheting and creep rupture lifetime. Thus, the maximum surface heat flux capability is determined not only by the mechanical properties of the first wall material but also by the key design parameters of the blanket.

The usual procedure of determining time-dependent primary membrane stress allowable by using section-averaged temperature and ignoring contribution of thermal stress to creep deformation may, under certain conditions, lead to unconservative results. The contribution of thermal stress to creep deformation and damage may be important for setting the peak surface heat flux limit on first wall materials that become embrittled during operation.

\section{References}

1. D. L. Smith et al., Blanket Comparison and Selection Study Final Report, ANL/FPP-84-1, Argonne National Laboratory, Argonne, IL, 1984.

2. Special Issue: ARIES-RS Tokamak Power Plant Design, Ed. M. S. Tillack, Fusion Engineering and Design, Vol. 38, 1997.

3. Y. Gohar, S. Majumdar, and D. L. Smith, High power density self-cooled lithium blanket, presented at the ISFNT-5, Rome, Sept. 19-24, 1999.

4. S. Majumdar and P. Smith, Treatment of Irradiation Effects in Structural Design Criteria for Fusion Reactors, Proc. 4th Intl. Symp. on Fusion Nucl. Tech. (ISFNT-4), Tokyo, April 6-11, 1997, also, Fus. Eng. Des., 41, (1998), 25-30. 
5. S. Majumdar, Structural Design Criteria for ITER, Proc. 13th ANS Top. Mtg. Technol. Fusion Energy, Nashville, June 7-11, 1998.

6. R. J. Kurtz and M. L. Hamilton, Biaxial thermal creep of V-4Cr-4Ti at $700^{\circ} \mathrm{C}$ and $800^{\circ} \mathrm{C}$, personal communication (1999).

7. M. Schirra, Das Zeitstandfestigkeits - und Kriechverhalten von Vanadin - Basis Legierungen, Rept. No. KfK 2440, Kernforschungszentrum Karlsruhe, Germany (1988). 


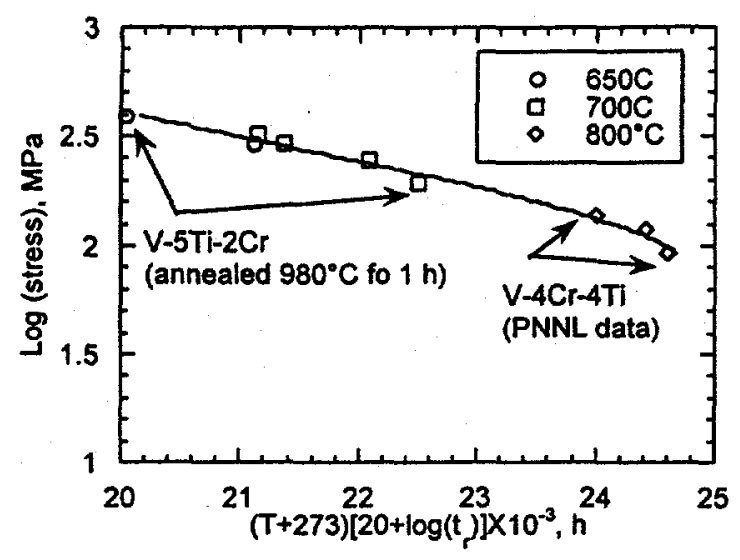

(a)

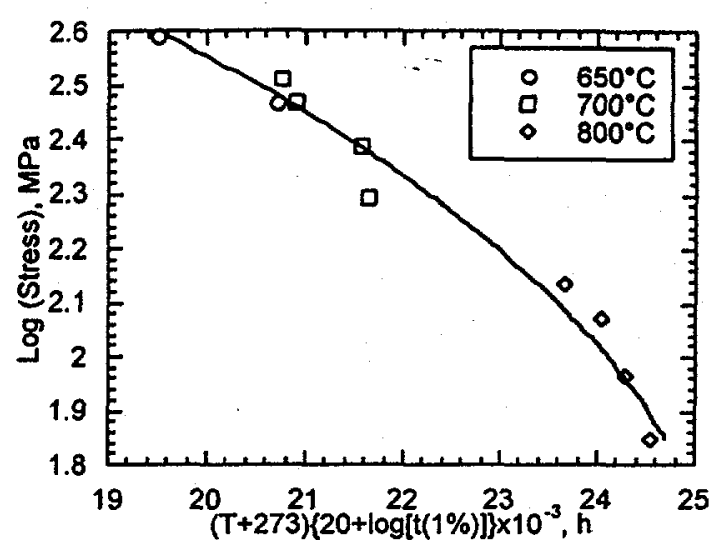

(b)

Fig. 1 Larson-Miller parameter plots of (a) creep rupture time and (b) time to $1 \%$ creep strain for V-alloys.

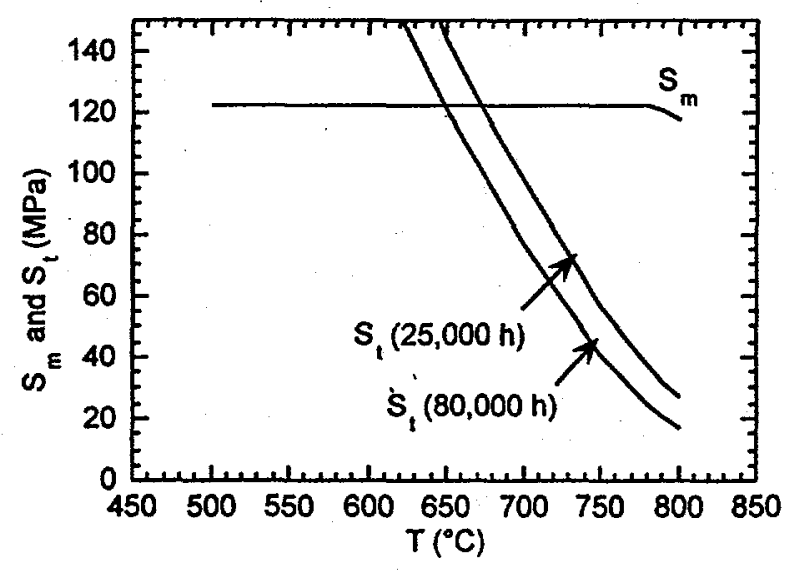

Fig. 2 Variation of $S_{m}$ and $S_{t}$ for V-alloys with temperature and design lifetime 


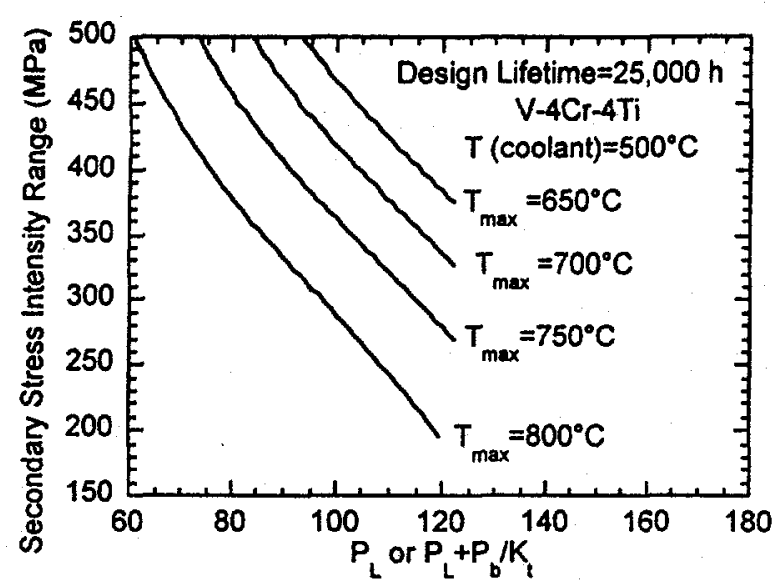

(a)

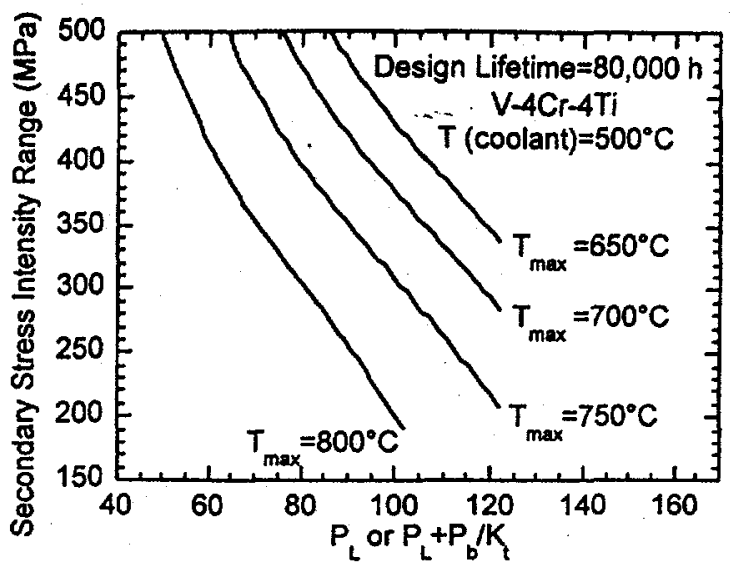

(b)

Fig. 3 Allowable cyclic secondary stress intensity range at various peak temperature of a Valloy first wall for given steady primary stress intensity for design lifetime of (a) $25,000 \mathrm{~h}$ and (b) $80,000 \mathrm{~h}$. The temperature of the first wall at the coolant edge, with surface heat flux on, is $550^{\circ} \mathrm{C}$ and the temperature at the "cool" end of the cycle is assumed to be the same as the coolant inlet temperature $\left(500^{\circ} \mathrm{C}\right)$.

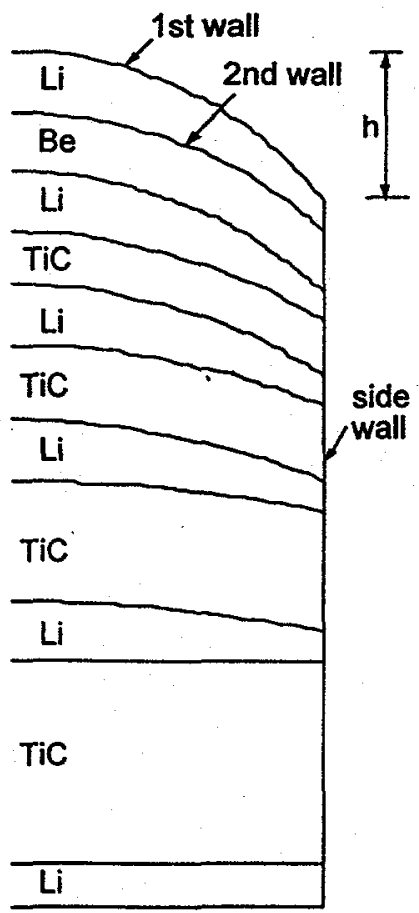

Fig. 4 Half of cross-section of high power density self-cooled lithium blanket with a curved first wall of height $h$. 


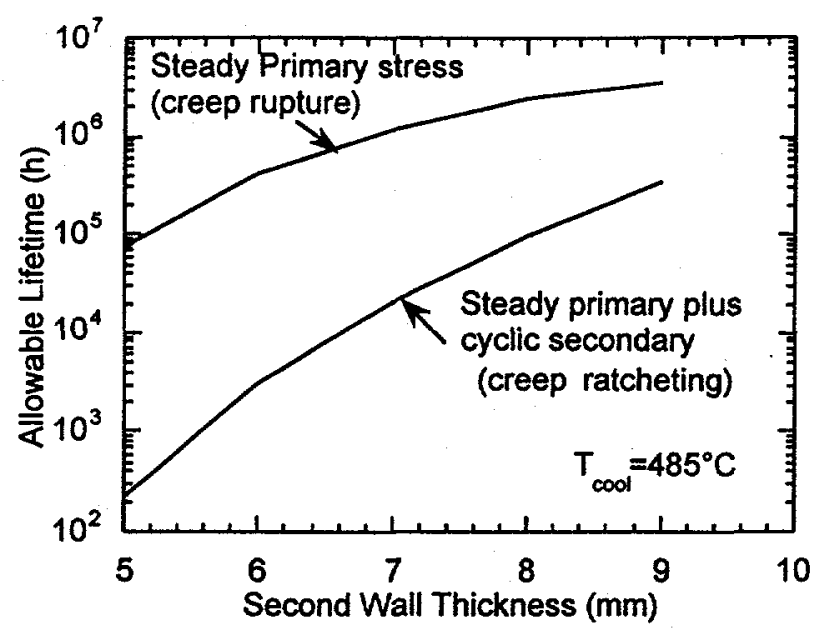

Fig. 5 Allowable lifetime at a surface heat flux of $2 \mathrm{MW} / \mathrm{m}^{2}$ vs. second wall thickness for satisfying primary stress and creep ratcheting rules. A toroidal span of $0.4 \mathrm{~m}$ with a first wall height $\mathrm{h}=10 \mathrm{~cm}$ is used.

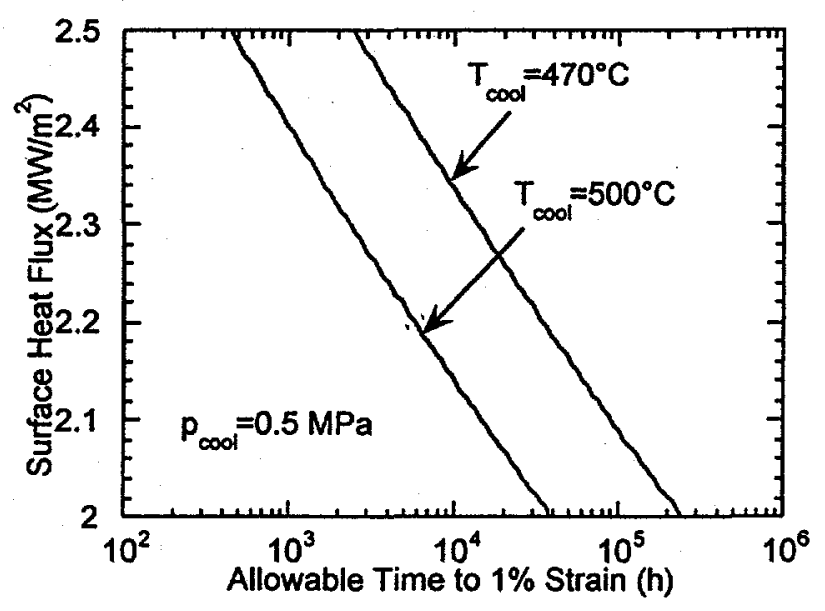

Fig. 6 Allowable surface heat flux on the reference design first wall to satisfy creep ratcheting rule versus lifetime as a function of the bulk coolant temperature 


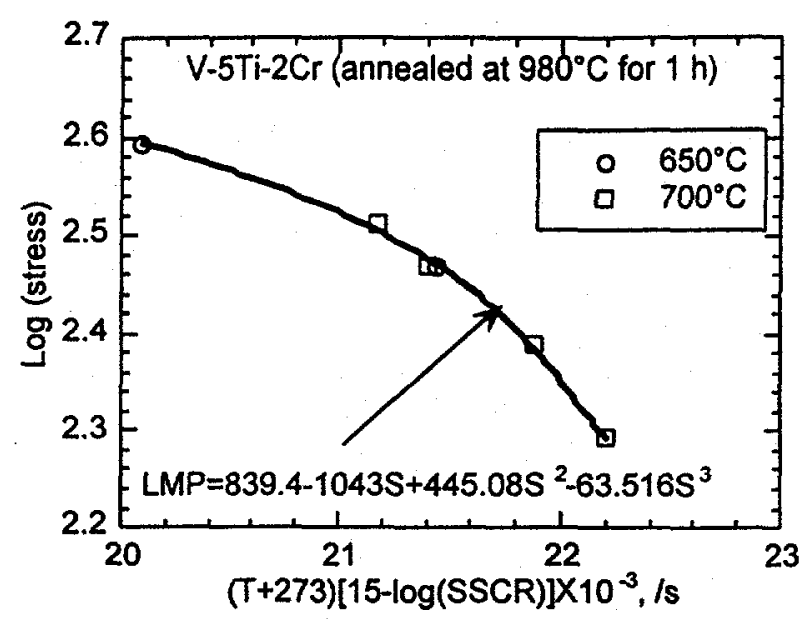

Fig. 7 Larson-Miller plot for steady state creep rate of V-5Ti-2Cr.

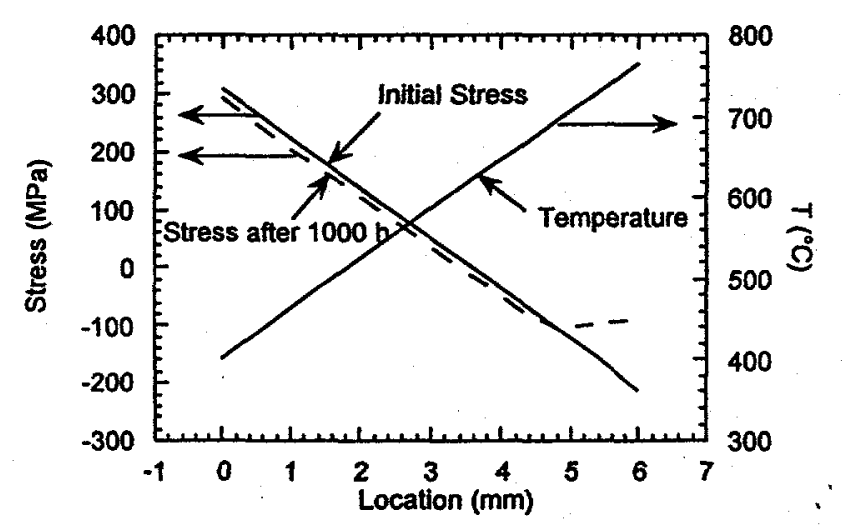

(a)

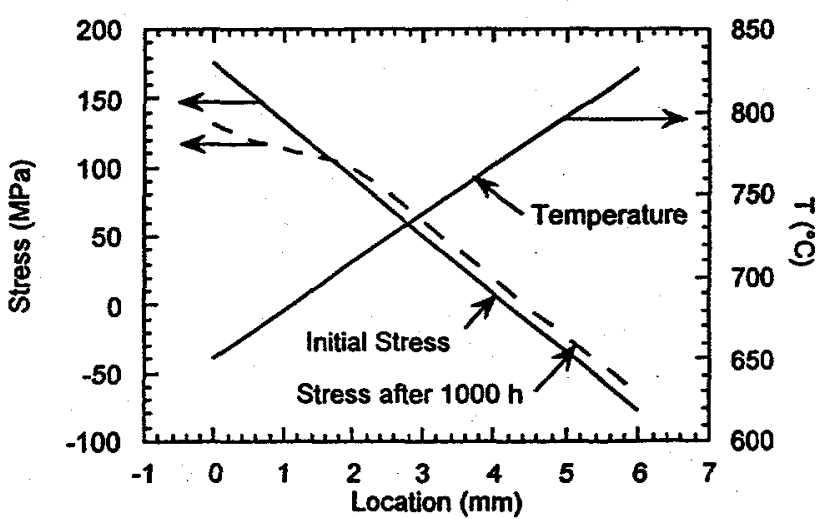

(b)

Fig 8 Temperature distributions in a $6 \mathrm{~mm}$ thick first wall due to a surface heat flux of (a) 2 $\mathrm{MW} / \mathrm{m}^{2}$ with a coolant side temperature of $400^{\circ} \mathrm{C}$ and (b) $1 \mathrm{MW} / \mathrm{m}^{2}$ with a coolant side temperature of $650^{\circ} \mathrm{C}$. Also shown are the initial stresses (solid line) and stresses after $1000 \mathrm{~h}$ (dotted line) due to thermal as well as a primary stress of $50 \mathrm{MPa}$. 


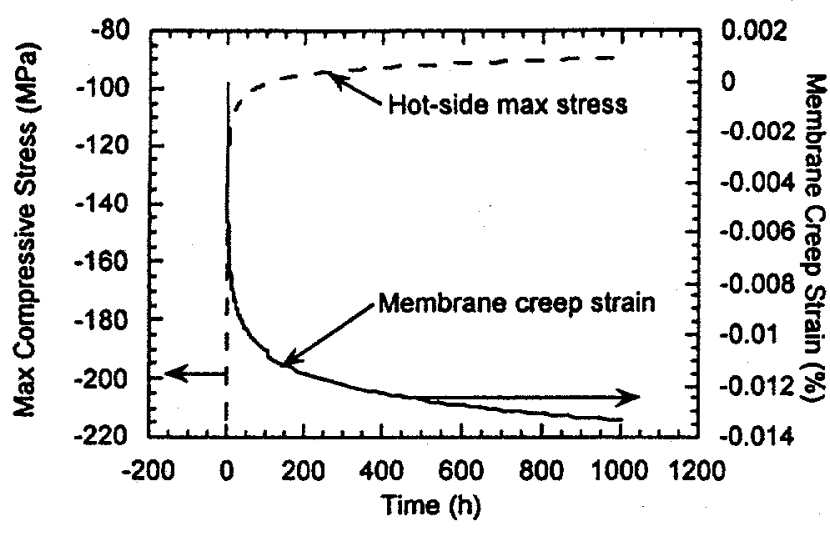

(a)

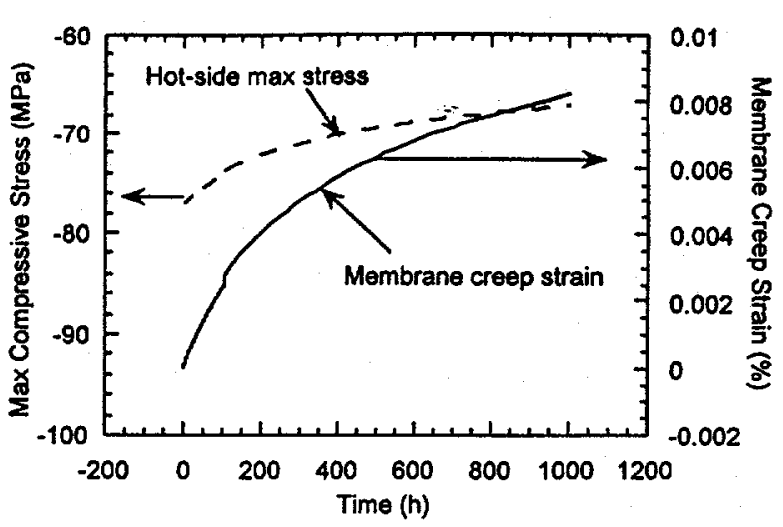

(b)

Fig. 9 Variations of peak compressive stress and membrane creep strain with time in a $6 \mathrm{~mm}$ thick first wall subjected to a primary membrane stress of $50 \mathrm{MPa}$ and a surface heat flux of (a) $2 \mathrm{MW} / \mathrm{m}^{2}$ with a coolant side temperature of $400^{\circ} \mathrm{C}$ and (b) $1 \mathrm{MW} / \mathrm{m}^{2}$ with a coolant side temperature of $650^{\circ} \mathrm{C}$.

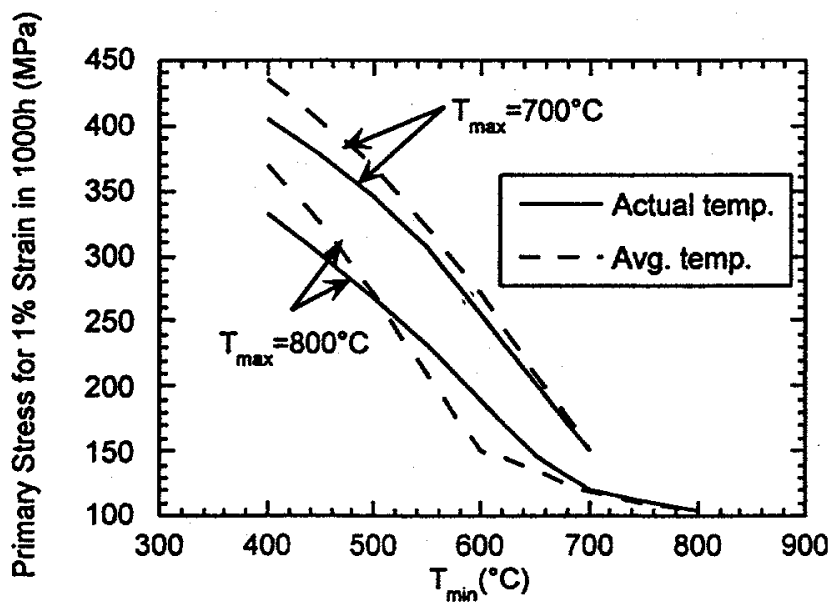

Fig. 10 Computed primary membrane stresses needed to accumulate $1 \%$ membrane creep strain in $1000 \mathrm{~h}$ in a $6 \mathrm{~mm}$ thick V-5Ti-2Cr plate with a temperature gradient (average thermal stress $=0$ ). Solid lines correspond to plates having temperatures varying between $T_{\min }$ and $\mathrm{T}_{\max }$ (i.e., primary plus thermal stresses) while dashed lines correspond to plates with a uniform average temperature (i.e., primary stress without thermal stress). 